\title{
The Effect of Visual Attention on Stereoscopic Lighting of Museum Ceramic Exhibits: A Virtual Environment Mixed with Eye-tracking
}

\author{
Xiaoqun Ai \\ College of Mechanical Engineering and Automation, Huaqiao University, Xiamen, China \\ College of Architecture, The Central Academy of Fine Arts, Beijing, China \\ E-mail: axq777@gmail.com \\ Zhendong $\mathrm{Wu}$ (corresponding author), Ting Guo, Jiayan Zhong, Nan Hu and Chunliu Fu \\ College of Mechanical Engineering and Automation, Huaqiao University, Xiamen, China \\ E-mail: wudesigner@gmail.com, 530060210@qq.com, 1206054699@qq.com,442004560@qq.com, \\ 1085889746@qq.com
}

Keywords: stereoscopic lighting, immersive virtual environment, eye-movement tracking, ceramic exhibit

Received: May 11, 2021

\begin{abstract}
Stereoscopic lighting is one of the influencing visual quality factors improving the visual presentation of ceramic exhibits. However, the current research only has a specific definition, and there is no clear measurement and evaluation method. This research adopted the method of bidirectional verification: psychophysical experiment and immersive virtual reality $(V R)$ with eye-movement tracking. We proposed a standard questionnaire for the stereoscopic visual experience. The eye-tracking data show that the visible fixation duration with stereoscopic lighting is $(M=5.18 \mathrm{~s})$, and the number of fixation points accounted for $63.48 \%$ of the whole number. Both indexes were higher than the situation without stereoscopic lighting. The result shows that the accuracy of finding the detail changes with or without stereoscopic lighting was $12.5 \%$ through the comparison of visual identification tasks, and finding modeling changes was $11.5 \%$. In the situation with stereoscopic lighting, the first identification frequency increased by $15.9 \%$ for small pattern changes of exhibits, as local modeling changes increased by $19 \%$. These results indicated that the stereoscopic lighting set according to the exhibits' volume could effectively improve the viewer's visual guide, strengthen the visual attention of the details, and model elements of the exhibits to achieve the optimal appreciation.
\end{abstract}

Povzetek: Pri stetoskopskem osvetljevanju muzejskih objektov so ugotavljali primerne rešitve za najboljši vtis na obiskovalcih.

\section{Introduction}

\subsection{Stereoscopic lighting}

Museum display lighting requires excellent colour rendering performance, better presentation of the shape and texture of the exhibits, and avoiding glare. The design is divided into nine main directions, namely uniformity, contrast, visual adaptation, apparent colour, colour rendering, exhibit background, glare, threedimensionality, accent lighting [1]. These factors also affect the visual salience and cognitive processing of the exhibit during viewing.

The stereoscopic lighting of modeling contains two meanings: one is to show the third-dimensional shape. Another is to play a role in highlighting some features or shielding local shortcomings according to the exhibition's needs. For museum display lighting, the performance of the shadow has a pivotal role in the ornamental value. If only the directional spotlight was used, the shadows will be too strong, making the exhibits too structured and strengthening the exhibits' stereoscopic lighting. If we only use the floodlight, the dim shadows would make the exhibits comply, giving people relaxation. Therefore, museum display lighting should make the exhibits have proper stereoscopic lighting and enable the details of exhibits to be fully displayed.

In the China national standard of lighting design [2], the exhibits' stereoscopic lighting should be expressed through the combination of directional lighting and diffused lighting. There is not a clear indicator or even definition that how to quantify the stereoscopic lighting of exhibits. In Japan, the illuminance ratio is set between 1/3 and $1 / 5$ for the scope of stereoscopic lighting. Due to the diverse modeling of exhibits, it is difficult to specify the stereoscopic lighting of all exhibits by only one formula and index range, because the actual workload and time costs are tremendous. Therefore, this study tries to study stereoscopic quantification for a certain kind of exhibit. The results can be applied and promoted in this kind of exhibit to achieve refining standards. Three formulas were used to express the stereoscopic lighting.

In this study, the second formula was used as a reference index for the museum showcase's lighting stereoscopic lighting. In the current ceramic exhibition area, most light sources use the floodlight and directional spotlight to gather light. Because of the unique bottom 

shrinkage modeling of ceramic exhibits, most light can not
Using stereoscopic lighting to strengthen visual

\begin{tabular}{|l|l|}
\hline The formula of stereoscopic lighting & \multicolumn{1}{|c|}{ Application and Characteristics } \\
\hline vector /scalar $(\vec{E} / E)$ & $\begin{array}{l}\text { Cuttle in The UK presented this formula in 1967, and this ratio has been } \\
\text { proved to play a role in " quantification ". Yun Si and Gongxia Yang (1980) } \\
\text { [3] also studied the visual environment of museum galleries, and drew the } \\
\text { conclusion of lighting conditions according to the exhibits with specific } \\
\text { modeling. It is generally believed that the figure is between in 1.2 and 1.8, } \\
\text { and the stereoscopic lighting of face is relatively great. }\end{array}$ \\
\hline $\begin{array}{l}\text { Average cylindrical } \\
\text { illuminance/horizontal illuminance } \\
\left.E_{c} / E_{h}\right)\end{array}$ & $\begin{array}{l}\text { Wenqing zhang (2007) [4] and Zhonglin chen (2009) [5] used this formula } \\
\text { to study the stereoscopic lighting index of urban lighting, and estimated } \\
\text { which index could better reflect the reality of objects and people. }\end{array}$ \\
\hline $\begin{array}{l}\text { Vertical illuminance/horizontal } \\
\text { illuminance }\left(E_{v} / E_{h}\right)\end{array}$ & $\begin{array}{l}\text { This is the simplest indicator of showing illumination directional effect and } \\
\text { stereoscopic lighting, but it is not accurate because it takes too few factors } \\
\text { into account. }\end{array}$ \\
\hline
\end{tabular}

Table 1: Indicators for evaluating the stereoscopic lighting of modeling.

irradiate to the exhibits' shrinking part. It resulted in a visual effect that the upper part is bright and the lower part is dark, making it impossible to see the patterns on the exhibits' side. A formula $\left(E_{c} / E_{h}\right)$ was used to solve this problem and obtaining a specific stereoscopic lighting ratio. According to this ratio, the experiment was conducted with different volumes of exhibits. It can help designers obtain suitable stereoscopic lighting ratio and provide new ideas for other types' stereoscopic experiments.

\subsection{Effects of illumination on visual saliency and cognitive processing}

As people perceived objects and captured information, visual attention focused on specific areas that were distinctly different from their surroundings in the scanned environment. When there was a more salient response to these environments, this feature was called visual saliency [6]. Specific features - such as brighter object surfaces tended to increase consistent visual behavior between observers [7]. Features such as brightness, contrast, and colour may influenced object saliency, attentional guidance, and the identification of search cues, and several scholars had proposed saliency-based approaches to modeling attention [8-9].

The non-visual effects of illumination were for cognitive processing. Studies by Scheer and Buijs confirm the arousal effect of illumination brightness on the brain [10]. Romine stated that a dynamic light environment with high colour temperature and frequency helped to improve attention [11]. Juslén et al. found that worker productivity increased significantly when higher colour temperatures were used and that lighting also worked by increasing visual sensitivity [12]. The effect of illumination on memory was related to task difficulty, with illumination levels having no significant impact on more difficult working memory tasks and a significant facilitation effect on easier tasks [13-14]. contrast to enhances the viewer's memory of exhibits is important for ceramic exhibits in museum space.

Firstly, aiming at bottom-up visual saliency, a human will produce a conditioned reflex for the information generated by objective objects, which is a rapid and unconscious stimulus way. By measuring the position of the fixations or the eye-movement that is relative to the head, a visual influence trend of the exhibit's lighting was obtained. Secondly, the conscious attention significance is measured with a cognitive experiment, which is a bottomup visual saliency, driven by Zheng Peng, (2004) [15]. Just and Carpenter (1980) proposed the Eye-Mind hypothesis that eye-movement provides dynamic tracking of attention allocation [16]. In a complex process of information processing, eye-movement and attention are inseparable [17]. In decades, the application of eyemovement tracking research involves the direction of information processing, such as reading, scene perception, visual search, and so on [18]. At present, few literatures have been found in the visual saliency triggered by stereoscopic lighting of museum exhibits.

\subsection{Visual attention test based on the stereoscopic lighting of exhibits in VE}

In recent years, many researchers have utilized virtual environment (VE) to help lighting design. It gradually becomes one of the academic circles' trends [19]. In the traditional lighting research, the laboratory scenes or reality were set up to conduct lighting research. To verify whether VE can simulate the effects of a real scene and the immersion and the authenticity of the VE's experimental results, scholars have done comparative experiments. Chen, Y (2018) [20] arranged a real lounge in the laboratory and constructed the same environment in VR. To compare the degree of authenticity, he also made video and photo replicas of the lounge and asked them to make a subjective evaluation in different environments. The result showed that the lighting attributes were consistent with the physical environment, and the similarity was 88.6 percent. $\mathrm{Xu}$ 
Chao (2018) [21] did a similar psychophysical experiment in the physical scene and VE, the experimental result showed that the participants in these two environments of colour temperature preference degree were same. Boyles (2009) had ever compared a 2D environment with a 3D cave environment. The result showed that 3D's evaluation of the subjects is better than the 2D environment [22]. The idea that VR was an indispensable technology for designers to express the lighting atmosphere in the city festival atmosphere's lighting design was proposed by Blandet (2011)[23] and Kim (2018)[24]. They said "VR technology can better understand and communicate with the projects." Balocco (2018) [25] set up a museum virtual reality environment and conducted tests on the illumination and colour perception of lights. He argued that conducting the experiment in software not only allows for a quick calculation of the energy loss of the light in that environment, but also obtained more scientific data such as the degree of attraction of the light source to the subject by performing statistics on physiological parameters.

The subtle changes of various light sources in the museum can be precisely controlled in VR, which balances the relationship between experimental control and ecological effectiveness. VR reduces the cost of time, and has the advantage of persistence. The viewer's visual behavior at the micro-level can be deeply analyzed by combining the eye-movement tracking device in VR. It verifies whether stereoscopic lighting improves the exhibits' visual significance and proves that whether the visual judgment of the viewer is more accurate.

\subsection{Hypotheses}

In this study, the stereoscopic lighting ratios changed in response to changes in lighting brightness, allowing for contrast between exhibits and their surroundings. This research focuses on the visual saliency and cognitive processing of museum's stereoscopic lighting. The specific questions are as follows:

-Does the visual salience of stereoscopic lighting in a museum space create an effective guide to visual attention?

-Does the enhanced visual contrast of stereoscopic lighting enhance awareness and memory of exhibits in other research areas?

-Can a cognitive questionnaire be used to measure subjects' perceptions of the visual experience of stereoscopic lighting in a virtual reality environment, and can a related task be used to measure subjects' cognitive efficiency and memory of exhibits?

In response to the above research questions, and based on the literature review, this study proposed a series of hypotheses to study of stereoscopic lighting in museums, as shown in the table 2 .

\section{Method in the first experiment}

\subsection{The abstract and quantified exhibit model}

The most common exhibits in a museum with similar modeling are selected as the representatives for the experiment. According to it, we researched stereoscopic lighting. According to its usage, size, and height, three common kinds of maximum cross-sectional area and three kinds of height size were summarized. We got nine different exhibit volumes through the cross-sections of these six values, and these nine sizes can match different types of exhibits: Chun Ping, Mei Ping, bowl, plate, basin, kettle, pot, vase. In order to exclude the influence of specific characteristics of exhibits for experimental results. We used the way that the $3 \mathrm{D}$ primitive ceramic model was made into experimental stimulus material. Besides its size, the material, colour etc., all these factors are similar to real ceramic exhibits. According to the characteristics of similar ceramic exhibits, we made the bottom shrinkage design for its modeling. The size and model corresponding to the category of exhibits are shown in the following Figure 2.

\subsection{Modeling and rendering}

In this experiment, we mainly used 3Ds max to achieve modeling, lighting design, adjusting, and testing. First of all, to established space with $6.0 \mathrm{~m}$ long, $6.0 \mathrm{~m}$ wide, and $3.0 \mathrm{~m}$ high as the museum's exhibition hall. Uniform illumination is used in the exhibition hall. The floor illumination is $200 \mathrm{~lx}$, and the uniformity illumination ratio is not less than 0.7 . The wall in the exhibition hall is covered with $50 \%$ medium gray with 0.7 reflection ratio. The floor is covered with $80 \%$ black with a 0.2 reflection ratio and lackluster. The ceiling is covered with $50 \%$ medium grey with a 0.7 reflection ratio and lackluster. A display cabinet with $0.8 \mathrm{~m}$ long, $0.8 \mathrm{~m}$ wide, and $2.2 \mathrm{~m}$ high is built in the room's center. The top illumination of the display cabinet consists of directional lighting and diffuse lighting. Moreover, the bottom illumination consists of diffuse lighting. The colour temperature of the light in the display cabinet is $3300 \mathrm{~K}$ all the time, the colour appearance features are warm, and the colour rendering index of the light source is 90 . The display cabinet is covered with $70 \%$ dark brown with 0.7 reflection ratio and lackluster, and with high transparency glass with 0.95 transmittances. The maximum average illumination of the exhibit surface should not exceed 300 lx [26-28].

\subsection{Intensity of stereoscopic lighting}

In this study, the numerical interval of stereoscopic lighting was set as $0.1,0.3,0.5,0.7,1,2,3$, and 4 . We got 72 pictures by adjusting the lighting illumination and rendering. The subjects watched these pictures in sequence and answered the questionnaire. The user's stereoscopic evaluation for different volumes of exhibits could be obtained. The specific stereoscopic values and 
corresponding average cylindrical illumination and horizontal illumination are shown in the Table 3.

\subsection{Procedure}

\subsubsection{Participants}

A total of 80 participants (47 women and 33 men) were selected to participate in the study, all of whom said they had not previously been exposed to such research. The

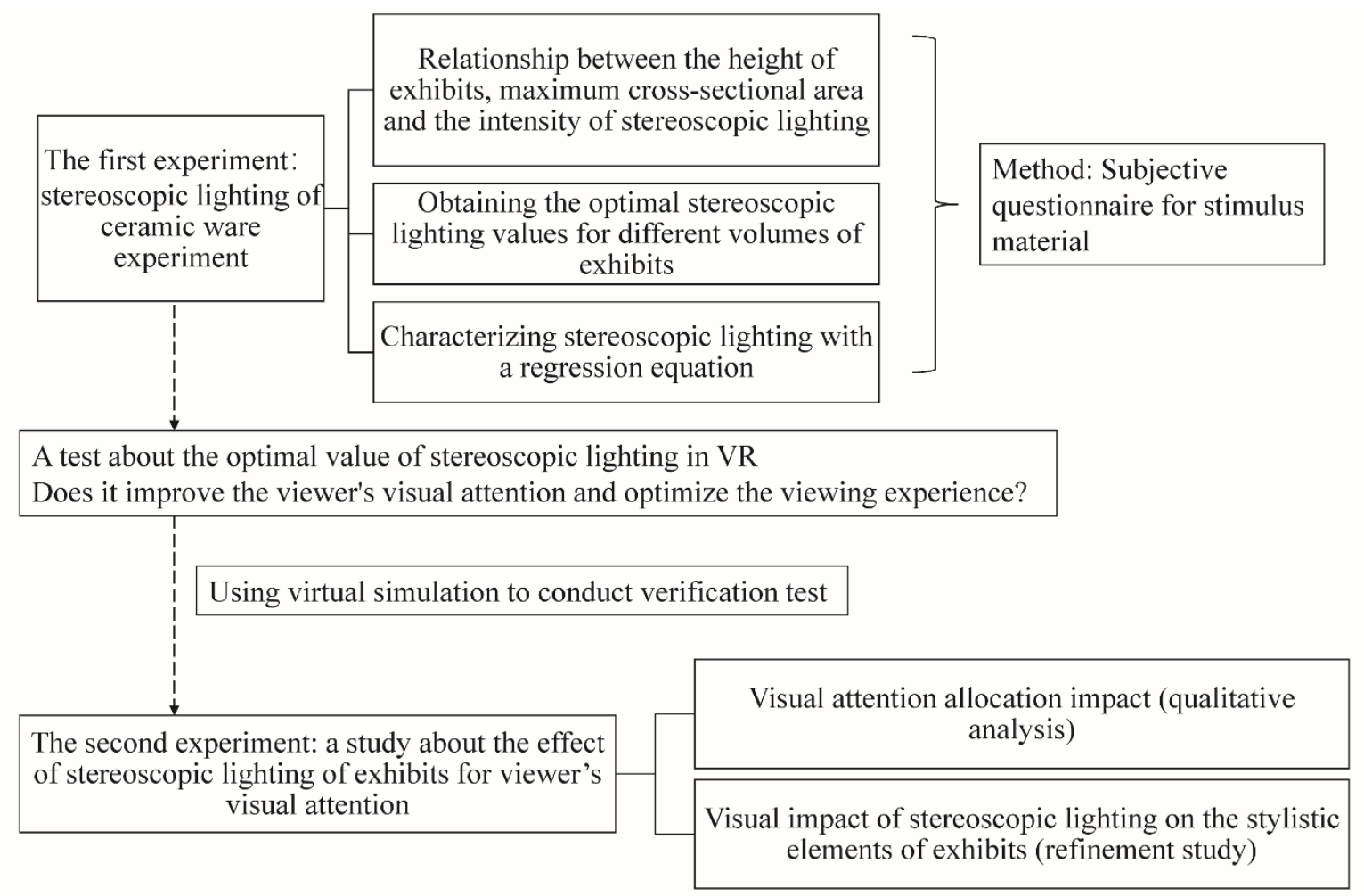

Figure 1: Experimental flow chart. For the first experiment: independent variables are the exhibit's height, maximum cross-sectional area and the stereoscopic lighting ratio. The dependent variable is viewer's visual experience. For the second experiment: independent variable is the optimal stereoscopic lighting ratio. The dependent variables are the visual attention and the cognitive efficiency. The study was divided into two experiments. Experiment one was mainly to describe the optimal stereoscopic lighting values of exhibits of different volumes. Experiment two was used to compare with the results of experiment one in VR.
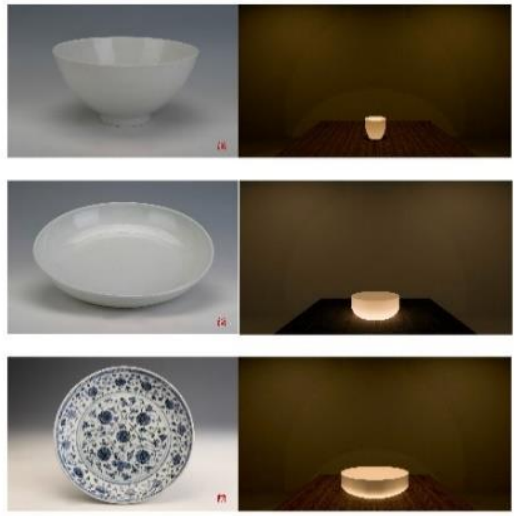
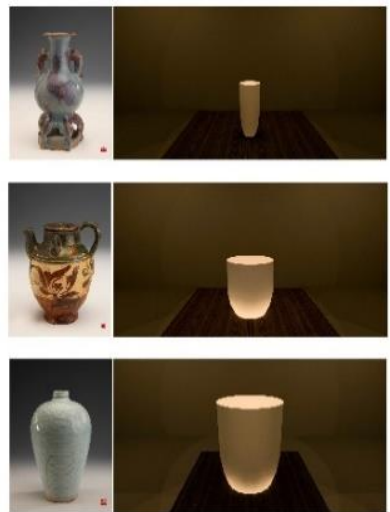
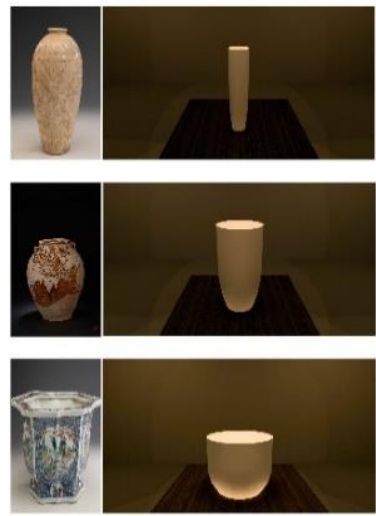

Figure 2: According to the size of the volume, the 3D primitive ceramic model is abstracted to the stimulus material used in the experiment. 
participant age was limited to a range of 18-28years (mean age: $22.2, \mathrm{SD}=2.5$ years). They all passed the Ishihara test to ensure that the experiment participants did not have colour blindness and colour weakness, and their vision or corrected vision was normal. The purposes of the study were not disclosed to the participants prior to the experiment. Seventy-two stimuli materials and 80 participants were divided into four groups, and each group tested 20 times.

\subsubsection{Instrument}

A 31-inch Dell LCD screen used to show stimulus materials, and the brightness and colour temperature of the screen was adjusted using an illuminometer. Show 18 materials in each group by Microsoft PowerPoint.

\subsubsection{Experimental design and procedure}

Participants were invited to stay in a quiet, airtight, and dark space, and we eliminated the effect of other light sources. The participants sited in front of the screen, and then one group of stimulation was shown before them. The observation time was $7 \mathrm{~s}$ for each stimulation. After observing, the screen automatically turned to the next blank page. At the same time, participants filled a subjective questionnaire. Then they continued to the next observation for stimulus by clicking the mouse, repeating these procedures until they finish the group's 18 stimulus materials. The whole experiment lasted about 30 minutes, each set of stimuli was played at random.

\subsection{Results and analysis of the first experiment}

In this experiment, Likert scale was adopted, and the subjects were asked to score the key words $3,2,1,0,-1$, 2 and -3 according to their feeling. The score changed from 3 to -3 represents the positive to a negative change in the word pairs. After the experiment, SPSS software was used to analyze the questionnaire data.

Before data analysis, $\alpha$ reliability coefficient method was used to conduct reliability analysis on the scale data. The results of reliability analysis show that Cronbach's alpha is 0.929 , and the reliability coefficient is high.

\begin{tabular}{|c|c|c|c|c|}
\hline \multicolumn{5}{|c|}{ The first experiment } \\
\hline \multirow{2}{*}{\multicolumn{2}{|c|}{ Dependent variable }} & \multicolumn{2}{|c|}{ Volume differences in exhibits } & \multirow{2}{*}{$\begin{array}{c}\text { Stereoscopic lighting } \\
\begin{array}{c}\text { Stereoscopic lighting } \\
\text { ratios }\end{array} \\
\end{array}$} \\
\hline & & Height & $\begin{array}{l}\text { Maximum cross-sectional } \\
\text { area }\end{array}$ & \\
\hline $\begin{array}{c}\text { Visual } \\
\text { Experience }\end{array}$ & $\begin{array}{l}\text { Likert scale } \\
\text { scores }\end{array}$ & $\begin{array}{l}\text { Subjects viewing exhibits } \\
\text { at different heights with } \\
\text { the same stereoscopic } \\
\text { lighting ratio had } \\
\text { different visual } \\
\text { experiences, scores on the } \\
\text { Likert scale are also } \\
\text { different. (H1) }\end{array}$ & $\begin{array}{l}\text { Subjects viewing exhibits } \\
\text { with different maximum } \\
\text { cross-sectional areas at the } \\
\text { same stereoscopic } \\
\text { illumination ratio had } \\
\text { different visual experiences, } \\
\text { scores on the Likert scale } \\
\text { are also different. (H2) }\end{array}$ & $\begin{array}{c}\text { Subjects viewing the } \\
\text { same exhibit at different } \\
\text { stereoscopic lighting } \\
\text { ratios had different } \\
\text { visual experiences, } \\
\text { scores on the Likert } \\
\text { scale are also different. } \\
\text { (H3) }\end{array}$ \\
\hline \multicolumn{5}{|c|}{ The second experiment } \\
\hline \multirow{2}{*}{\multicolumn{2}{|c|}{ Dependent variable }} & \multicolumn{3}{|c|}{ the optimal stereoscopic lighting ratios } \\
\hline & & \multicolumn{3}{|c|}{ With and without optimal stereoscopic lighting } \\
\hline \multirow{2}{*}{$\begin{array}{l}\text { Visual } \\
\text { attention }\end{array}$} & $\begin{array}{l}\text { Duration of } \\
\text { fixation }\end{array}$ & \multicolumn{3}{|c|}{$\begin{array}{l}\text { Subjects viewed the exhibits with and without optimal stereoscopic lighting and their } \\
\text { duration of fixation were different, with longer duration of fixation for the exhibits } \\
\text { with optimal stereoscopic lighting. (H4) }\end{array}$} \\
\hline & Fixation & \multicolumn{3}{|c|}{$\begin{array}{l}\text { Subjects viewed the exhibits with and without optimal stereoscopic lighting and their } \\
\text { fixations were different, with more fixations for the exhibits with optimal } \\
\text { stereoscopic lighting. (H5) }\end{array}$} \\
\hline \multirow{2}{*}{$\begin{array}{l}\text { Cognitive } \\
\text { efficiency }\end{array}$} & $\begin{array}{l}\text { Correct rate } \\
\text { of finding } \\
\text { change }\end{array}$ & \multicolumn{3}{|c|}{$\begin{array}{l}\text { Subjects viewed the exhibits with and without optimal stereoscopic lighting and their } \\
\text { correct rate of finding change was different, with a higher correct rate of finding } \\
\text { change for the exhibits with optimal stereoscopic lighting. (H6) }\end{array}$} \\
\hline & $\begin{array}{l}\text { Frequency } \\
\text { of the first } \\
\text { finding } \\
\text { changes }\end{array}$ & \multicolumn{3}{|c|}{$\begin{array}{l}\text { Subjects viewed the exhibits with and without optimal stereoscopic lighting. Their } \\
\text { correct rate of finding change was different, with a higher correct rate of finding } \\
\text { change for the exhibits with optimal stereoscopic lighting. }(\mathrm{H} 7)\end{array}$} \\
\hline
\end{tabular}

Table 2: Hypotheses for the first and second experiment. 
Before using factor analysis, KMO value and Bartley's spherical test were carried out on the questionnaire data of 8 three-dimensional sense values of each exhibit's volume. The results showed that KMO value was close to 1 , and the correlation between variables was strong, and the partial correlation was weak. In all Bartley sphericity

\begin{tabular}{|c|c|c|c|c|c|c|c|c|c|}
\hline \multirow{2}{*}{$\begin{array}{c}\text { Maximum cross- } \\
\text { sectional area }\left(\mathrm{m}^{2}\right)\end{array}$} & \multicolumn{3}{|c|}{0.01} & \multicolumn{3}{|c|}{0.05} & \multicolumn{3}{|c|}{0.1} \\
\hline & 0.1 & 0.3 & 0.5 & 0.1 & 0.3 & 0.5 & 0.1 & 0.3 & 0.5 \\
\hline & & 1 & $1 \mathrm{r}$ & $=$ & J & $\tau$ & $=$ & こ & E \\
\hline $\begin{array}{l}\text { The stereoscopic } \\
\text { lighting indexes }\end{array}$ & 0.1 & 0.1 & 0.1 & 0.1 & 0.1 & 0.1 & 0.1 & 0.1 & 0.1 \\
\hline $\begin{array}{c}\text { Average cylindrical } \\
\text { illuminance }\end{array}$ & 30 & 30 & 30 & 30 & 30 & 30 & 30 & 30 & 30 \\
\hline &. & 1 & I & $=$ & J & $J$ & $=$ & E & $\bar{J}$ \\
\hline $\begin{array}{l}\text { The stereoscopic } \\
\text { lighting indexes }\end{array}$ & 0.3 & 0.3 & 0.3 & 0.3 & 0.3 & 0.3 & 0.3 & 0.3 & 0.3 \\
\hline $\begin{array}{l}\text { Average cylindrical } \\
\text { illuminance }\end{array}$ & 90 & 90 & 90 & 90 & 90 & 90 & 90 & 90 & 90 \\
\hline & 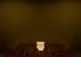 & 1 & $\mathrm{I}$ & $=$ & o & J & $=$ & e & $\bar{v}$ \\
\hline $\begin{array}{l}\text { The stereoscopic } \\
\text { lighting indexes }\end{array}$ & 0.5 & 0.5 & 0.5 & 0.5 & 0.5 & 0.5 & 0.5 & 0.5 & 0.5 \\
\hline $\begin{array}{c}\text { Average cylindrical } \\
\text { illuminance }\end{array}$ & 150 & 150 & 150 & 150 & 150 & 150 & 150 & 150 & 150 \\
\hline $\begin{array}{l}\text { The stereoscopic } \\
\text { lighting indexes }\end{array}$ & 0.7 & 0.7 & 0.7 & 0.7 & 0.7 & 0.7 & 0.7 & 0.7 & 0.7 \\
\hline $\begin{array}{c}\text { Average cylindrical } \\
\text { illuminance }\end{array}$ & 210 & 210 & 210 & 210 & 210 & 210 & 210 & 210 & 210 \\
\hline & . & 1 & 1 & . & 0 & $\pi$ & 음 & 무 & U \\
\hline $\begin{array}{l}\text { The stereoscopic } \\
\text { lighting indexes }\end{array}$ & 1 & 1 & 1 & 1 & 1 & 1 & 1 & 1 & 1 \\
\hline $\begin{array}{c}\text { Average cylindrical } \\
\text { illuminance }\end{array}$ & 300 & 300 & 300 & 300 & 300 & 300 & 300 & 300 & 300 \\
\hline & & I & & 0 & 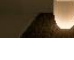 & & 0 & $1-$ & $v$ \\
\hline $\begin{array}{l}\text { The stereoscopic } \\
\text { lighting indexes }\end{array}$ & 2 & 2 & 2 & 2 & 2 & 2 & 2 & 2 & 2 \\
\hline $\begin{array}{c}\text { Average cylindrical } \\
\text { illuminance }\end{array}$ & 300 & 300 & 300 & 300 & 300 & 300 & 300 & 300 & 300 \\
\hline & 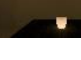 & 1 & & & C & 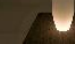 & 0 & E & $U$ \\
\hline $\begin{array}{l}\text { The stereoscopic } \\
\text { lighting indexes }\end{array}$ & 3 & 3 & 3 & 3 & 3 & 3 & 3 & 3 & 3 \\
\hline $\begin{array}{c}\text { Average cylindrical } \\
\text { illuminance }\end{array}$ & 300 & 300 & 300 & 300 & 300 & 300 & 300 & 300 & 300 \\
\hline & & 1 & $\mathrm{I}$ & & 0 & 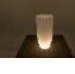 & 0 & 0 & U \\
\hline $\begin{array}{l}\text { The stereoscopic } \\
\text { lighting indexes }\end{array}$ & 4 & 4 & 4 & 4 & 4 & 4 & 4 & 4 & 4 \\
\hline $\begin{array}{c}\text { Average cylindrical } \\
\text { illuminance }\end{array}$ & 300 & 300 & 300 & 300 & 300 & 300 & 300 & 300 & 300 \\
\hline
\end{tabular}

Table 3: A gather of stimulus materials. 


\begin{tabular}{|c|c|}
\hline Keywords & \\
\hline 1. hostile-friendly & \multirow{9}{*}{$\begin{array}{l}\text { Standard Questionnaire in Visual Environment [29-30] } \\
\text { Optimal lighting conditions questionnaire in museum } \\
\text { showrooms }\end{array}$} \\
\hline 2. unpleasant-pleasant & \\
\hline 3. unnatural-harmonious & \\
\hline 4. unaesthetic-beautiful & \\
\hline 5. negative-positive & \\
\hline 6. dim-bright & \\
\hline 7. distracted-focused & \\
\hline 8. informal-formal & \\
\hline 9. unsatisfied-satisfied & \\
\hline 10. uncomfortable-comfortable & \multirow{4}{*}{ Spatial perception questionnaire [31-33] } \\
\hline 11. rigid-soft & \\
\hline 12. uneven-even & \\
\hline 13. depressed-relaxed & \\
\hline 14. cold-hot & \multirow{2}{*}{ Deep interview for user } \\
\hline 15. round-sharp & \\
\hline 16. nervous-excited & \multirow{3}{*}{$\begin{array}{c}\text { PAD Mood questionnaire [34-35] } \\
\text { User behavior trend questionnaire [36-38] }\end{array}$} \\
\hline 17. dominated & \\
\hline 18. wanting to leave- wanting to get close & \\
\hline
\end{tabular}

Table 4: Stereoscopic influence factors questionnaire.

tests, $\mathrm{P}=0.000<0.05$, and there is a correlation between the variables, and the factor analysis is effective.

Principal component analysis was used for the questionnaire data, and the initial characteristic value in the program was set at 1.0. Every exhibit obtained 2-4 principal factors, and their cumulative contribution rate reached more than $60 \%$. SPSS calculated the composite factor scores, and the composite factor scores were obtained when the maximum cross-sectional area and height were determined and different stereoscopic ratios were obtained.

\section{The second method}

\subsection{VR lighting display}

There are two VR scenes were set up in the experiment. In the first scene, the display cabinets' exhibits were not designed with stereoscopic lighting, and only the directional and diffuse lighting at the top was used for lighting. In the second scene, exhibits were designed with stereoscopic lighting. The optimal stereoscopic lighting value was the values which obtained in the previous experiment. To control the variables, the lighting data in the experiment was obtained through the "lighting analyses" in the Vray plug-in. After determining the lights' illumination level, a $360^{\circ}$ simulated image of $8000 * 4000$ pixels were rendered by the model. To simulate the viewpoint of the audience, the camera was rendered at the center of the exhibition hall with a height of $1.6 \mathrm{~m}$. The experimental errors were all within 5\%. The VR setting is shown in Figure 3.

The final 8 VE were obtained, divided into 2 categories according to a stereoscopic lighting design. The original VE without stereoscopic lighting design was numbered 1-1, while the original scene with stereoscopic lighting design was numbered 2-1. Scenes without stereoscopic lighting with colour, detail, and modeling changes were numbered 1-2,1-3, and 1-4 in order, while scenes with stereoscopic lighting design were numbered 2-2, 2-3, and 2-4 in order.

\subsection{Procedure}

\subsubsection{Participants}

A total of 36 participants (18 women and 18 men) were selected to participate in the study, all of whom said they 
had not previously been exposed to such study. The participant age was limited to a range of 18-25years (mean age: $22.5, \mathrm{SD}=1.5$ years). They all passed the Ishihara test to ensure that the participants in the experiment did not have colour blindness and colour weakness, and their vision or corrected vision was normal. The purposes of the study were not disclosed to the participants entered an eye-tracking test environment shown in Figure 5. They then were asked to view exhibits freely for 20 seconds when we collected eye-tracking data simultaneously.

The second part was a task experiment, in which 18 participants entered VE 1-1, observed and memorized the features of the exhibits, and then randomly switched to one

\begin{tabular}{|c|c|c|c|c|c|c|c|c|c|}
\hline \multirow{2}{*}{$\begin{array}{c}\text { Stereoscopic } \\
\text { ratios }\end{array}$} & \multicolumn{8}{|c|}{ maximum cross-sectional area $\left(m^{2}\right) /$ height $(\mathrm{m})$} \\
\cline { 2 - 10 } & $0.01 / 0.1$ & $0.01 / 0.3$ & $0.01 / 0.5$ & $0.05 / 0.1$ & $0.05 / 0.3$ & $0.05 / 0.5$ & $0.1 / 0.1$ & $0.1 / 0.3$ & $0.1 / 0.5$ \\
\hline 0.1 & -2.24 & -8.58 & 1.08 & -1.2 & -9.06 & -3.84 & 1.18 & 1.61 & 0.65 \\
\hline 0.3 & -1.66 & -2.77 & -1.92 & -3.12 & -2.62 & -1.85 & 3.68 & 5.98 & 3.42 \\
\hline 0.5 & 2.34 & -0.8 & -0.19 & 1.17 & 3.11 & 8.15 & 3.23 & 4.48 & 3.46 \\
\hline 0.7 & -0.92 & 2.44 & 1 & 0.82 & 2.62 & 1.51 & 3.23 & -1.55 & 0.6 \\
\hline 1 & 3.06 & 3.88 & 0.69 & 5.13 & 1.32 & -1.27 & 0.07 & -3.21 & -3.98 \\
\hline 2 & -0.59 & 3.46 & 2.99 & -3.95 & 2.98 & -1.86 & -0.7 & -2.57 & -0.39 \\
\hline 3 & 3.44 & 1.25 & -1.12 & 1.54 & -0.09 & -0.22 & -8.02 & -0.7 & -0.44 \\
\hline 4 & -3.25 & 1.3 & -2.56 & -0.42 & 1.8 & -0.6 & -2.7 & -4.05 & -3.44 \\
\hline
\end{tabular}

Table 5: Comprehensive factor scores summary of SD Semantic Scale The table shows the comprehensive factor scores of the scale under the experimental setting of the maximum cross-sectional area/height of the enclosure and the corresponding stereoscopic ratio.

participants prior to the experiment.

\subsubsection{Equipment}

In this experiment, data including duration of fixation and fixation were collected using a virtual reality device, HTC Vive Pro Eye, which can track eye movement images and immediately generate derived data, with a data output frequency of $120 \mathrm{~Hz}$ and a precision of 0.5 degrees to 1.1 degrees. The device used a dual OLED display with a total resolution of $2880 \times 1600$ pixels and 615 PPI. The $360 \mathrm{VR}$ images were programmed by Tobii Pro Lab software, which was used for experimental design and eye movement data analysis. The brand of the illuminometer is PEAKMETER and the model is PM6612L. The illuminometer is calibrated once a year in accordance with the code of use to ensure the accuracy in use.

\subsubsection{Experimental design and procedures}

The first part was eye movement experiment, using the stereoscopic lighting in the display cabinets as a variable in the same VE. As Figure 4 showed, the first, third, fifth, seventh, and ninth display cabinets from the left in the scene had stereoscopic lighting design, while the rest did not. This was mainly used to compare whether stereoscopic lighting design in the same environment impacted the visual attention.

In this experiment, 36 participants were divided into two groups. After visual calibration, one group of of VE 1-2, 1-3, or 1-4 (1-2, 1-3, 1-4 were scenes with changes in modeling or colour or details from 1-1), and were asked to find something different from scene 1-1.

The experimenter recorded the correct rate of task completion and task completion time. After completing the first difference-finding task, the participants entered VE 2-1, memorized the features of the exhibits, and then randomly switched to one of the scenes $2-2,2-3$, or 2-4 in the same way $(2-2,2-3,2-4$ were scenes with changes in modeling or colour or details from 2-1). The participants were asked to find something different from the scene 2 1. Participants would not repeat the experiment in the difference-finding task between the first time and the second time. For example, the scene where the participants found the difference for the first time was 12 , and then only scene $2-3$ or scene $2-4$ would randomly appear in the second time for the difference. The participants would not enter scene 2-2. The other 18 participants' experiment process was the same as that of the first 18 participants, except that this part of the participants would first enter scene 2-1 to do the differentfinding task and then entered scene 1-1 to do the second different-finding task. 


\subsection{Data analysis and results}

\subsubsection{Duration of fixation analysis}

The duration of fixation is the sum of the time spent observing an area, which is an important indicator of interest in a particular area of interest. The longer the duration of fixation, the higher interest level in a particular area of interest. Before analyzing the duration of fixation, the VE was divided into two areas of interest based on whether the exhibit was designed with stereoscopic lighting, as shown in Figure 5.
As Figure 6 showed, the duration of fixation in the area of interest with stereoscopic lighting $(\mathrm{M}=5.18 \mathrm{~s}, \mathrm{SD}$ $=2.14$ ) was significantly greater than that without stereoscopic lighting $(\mathrm{M}=2.86 \mathrm{~s}, \mathrm{SD}=1.64)$. A onesample T-test was used to verify whether there was a significant effect on the duration of fixation. There was an outlier in the data of the difference in duration of fixation between the two areas of interest, as shown in the Figure 7. To perform data transformation, the outlier was replaced with the mean of the difference in fixation duration. The replaced data passed the normality test $(\mathrm{p}>$ $0.05)$, as shown in the Table 7. Table 8 showed a statistically significant difference in duration of fixation
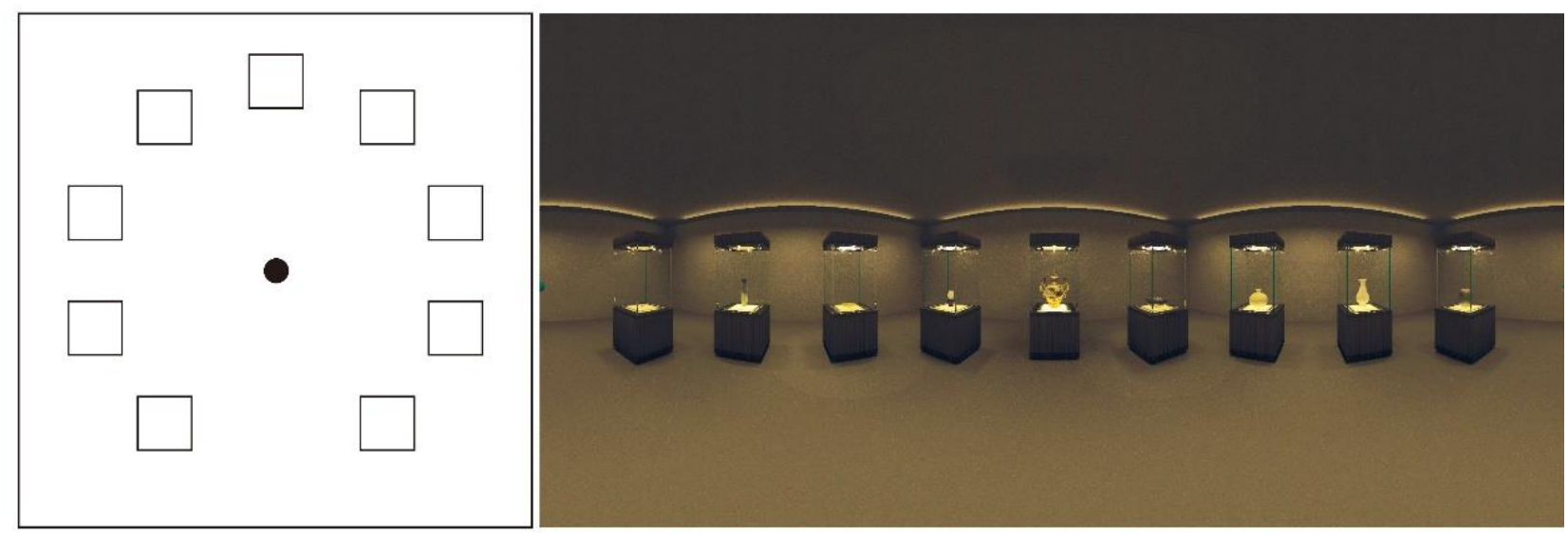

Figure 3: Schematic diagram of the direction and position of the exhibition cabinets and VR used in this experiment, the black dot in the center of the figure on the left is the position of participants in VR in this experiment, in addition to verifying the experience of multiple exhibits with and without stereoscopic lighting design, a task test was conducted to determine which factors of exhibit change viewers were more sensitive to. According to the first experiment results, exhibit changes were classified into three types of colour, detail, and modeling changes, and 2-3 exhibits in the original VE have modified accordingly, as shown in Table 6.

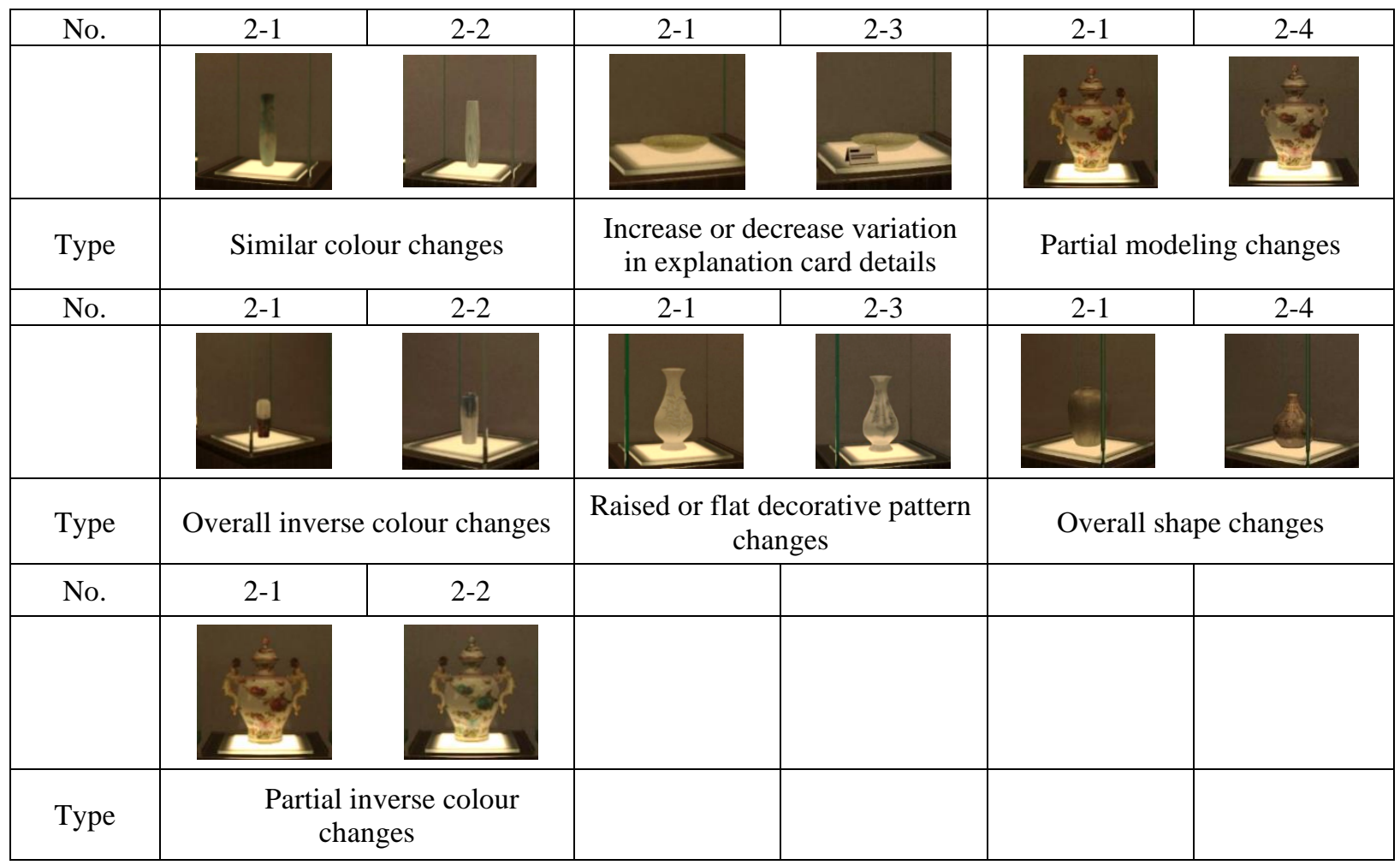

Table 6: Comparison before and after the change of exhibits in VE 2-1. 


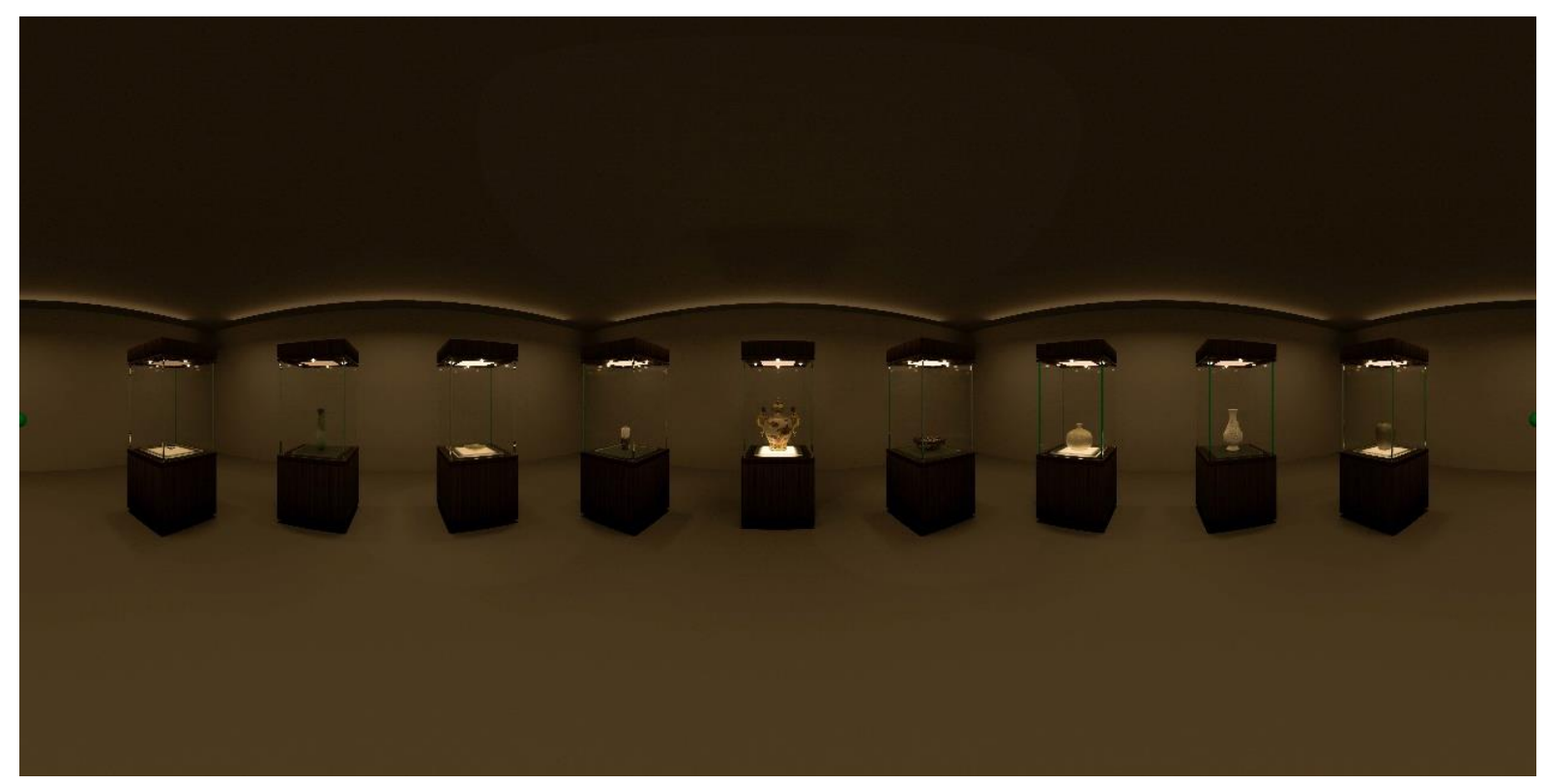

Figure 4: 360 VR image environment used in eye movem nt experiment. The first, third, fifth, seventh, and ninth display cabinets from the left in the scene had stereoscopic lighting design, while the rest did not.

between the area of interest with and without stereoscopic lighting $(p<0.05)$, indicating that stereoscopic lighting had a substantial effect on the participants' fixation duration.

As Figure 6 showed, the duration of fixation in the area of interest with stereoscopic lighting $(\mathrm{M}=5.18 \mathrm{~s}, \mathrm{SD}$ $=2.14$ ) was significantly greater than that without stereoscopic lighting $(\mathrm{M}=2.86 \mathrm{~s}, \mathrm{SD}=1.64)$. A onesample T-test was used to verify whether there was a significant effect on the duration of fixation. There was an outlier in the data of the difference in duration of fixation between the two areas of interest, as shown in the Figure 7. To perform data transformation, the outlier was replaced with the mean of the difference in fixation duration. The replaced data passed the normality test ( $\mathrm{p}>$ 0.05 ), as shown in the Table 7 . Table 8 showed a statistically significant difference in duration of fixation between the area of interest with and without stereoscopic lighting $(\mathrm{p}<0.05)$, indicating that stereoscopic lighting had a substantial effect on the participants' fixation duration.

\subsubsection{Fixation analysis}

Fixation refers to the sum of the number of all fixation points in the area of interest. It indicates the number of visual stays in the area of interest and is strongly related to fixation duration.

The results in Figure 8 showed that fixations in interest areas with stereoscopic lighting $(\mathrm{M}=27.33 \mathrm{~s}, \mathrm{SD}$ $=8.35$ ) were significantly greater than fixations in the area of interest without stereoscopic lighting $(\mathrm{M}=15.72 \mathrm{~s}, \mathrm{SD}$ $=6.35$ ). Fixations with stereoscopic lighting accounted for $63.48 \%$ of the total fixations, and fixations without stereoscopic lighting accounted for $36.52 \%$ of the total fixations.

Besides, a one-sample T-test was used to verify whether stereoscopic lighting had a significant impact on fixation. The data for the difference in fixations have no outliers as shown in Figure 9 and pass the normality test ( $p>0.05$ ) as shown in Table 9. The results in Table 10 showed a statistically significant difference in fixation in the area of interest with and without stereoscopic lighting $(\mathrm{P}<0.05)$, which indicated that stereoscopic lighting had a substantial effect on the fixation of participants.

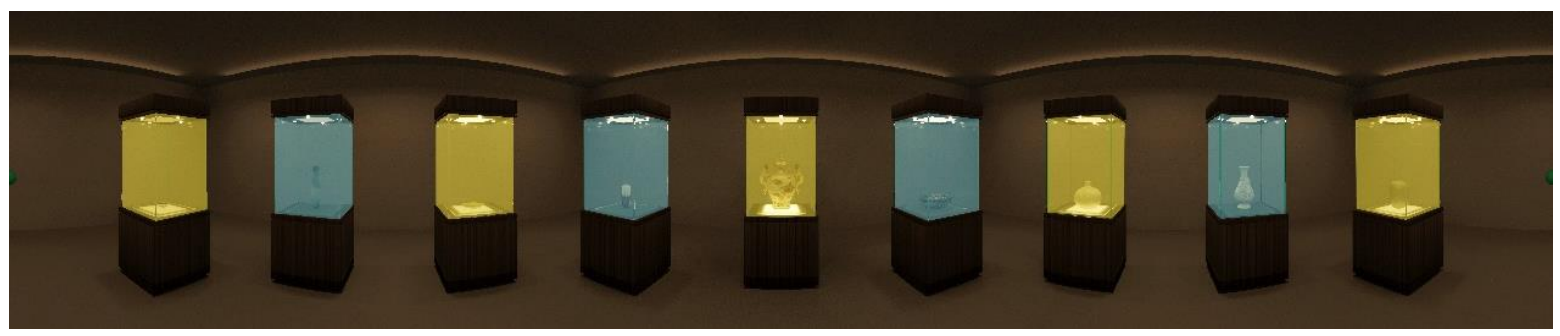

Figure 5: Segmentation of the scene's area of interest: the yellow area in the figure is the area of interest for exhibits with stereoscopic light and the green block is the area of interest for exhibits without stereoscopic light. 
In summary, these results showed that the exhibits with stereoscopic lighting attracted more attention, both in terms of fixation and fixation duration. Furthermore, the participants were more likely to pay attention to the exhibits with stereoscopic lighting when they were in a free state.

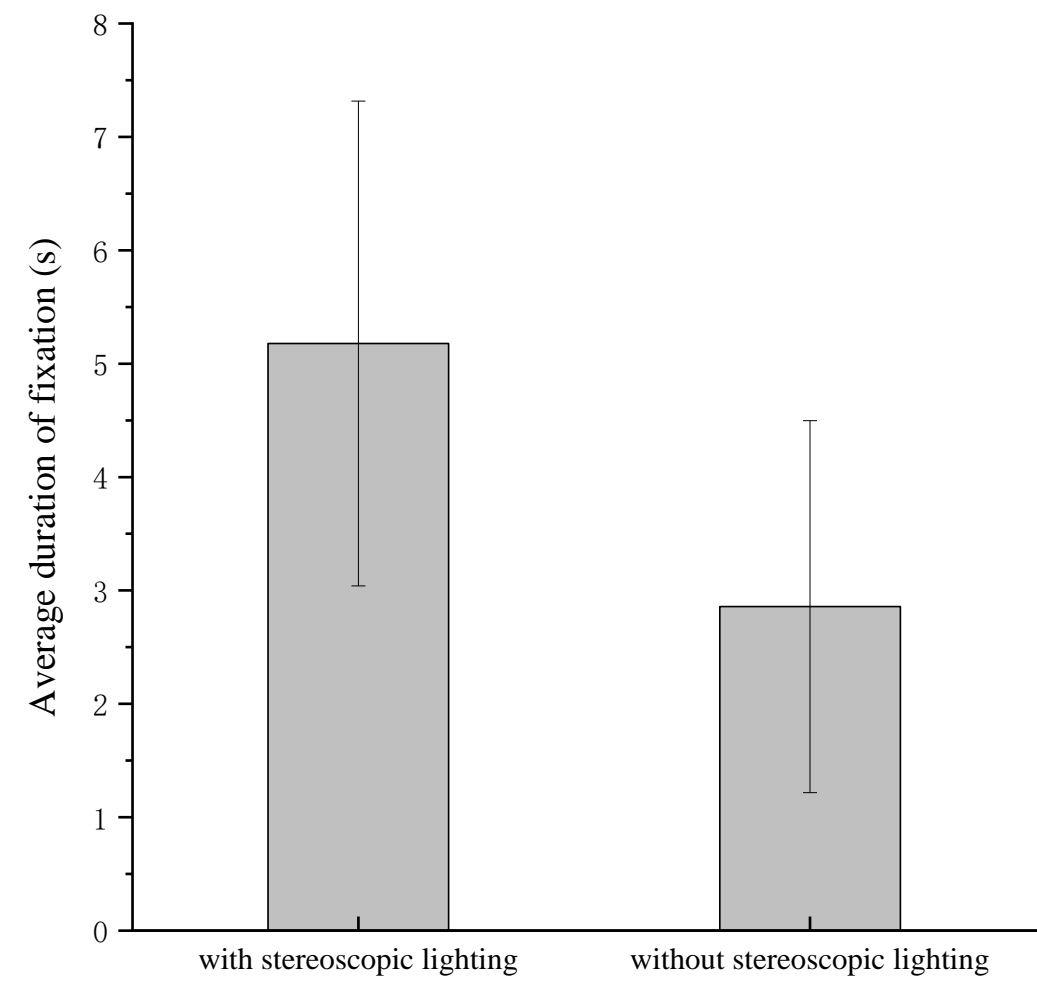

Figure 6: Average duration of fixation in areas of interest with or without stereoscopic lighting in the second experiment. The error bars in this figure are the standard deviation of duration of fixation.

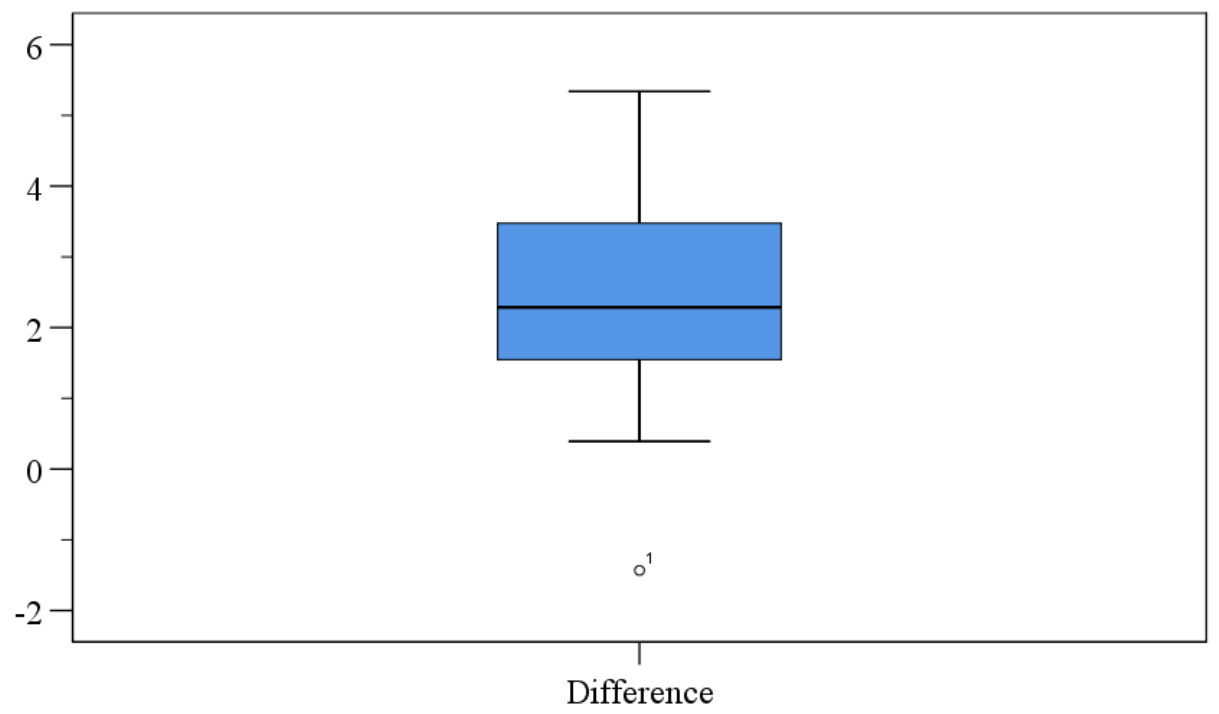

Figure 7: Box plot of the difference in duration of fixation.

\begin{tabular}{|c|c|c|c|c|c|c|}
\hline \multirow{2}{*}{} & \multicolumn{3}{|c|}{ Kolmogorov $^{\mathrm{a}}$} & \multicolumn{3}{c|}{ Shapiro-Wilk } \\
\cline { 2 - 7 } & Statistic & df & Sig & Statistic & df & Sig \\
\hline $\begin{array}{c}\text { Difference after data } \\
\text { conversion }\end{array}$ & .172 & 18 & .167 & .959 & 18 & .590 \\
\hline a. Lilliefors Significance Correction.
\end{tabular}

Table 7: Normality test of the difference after data transformation. 


\subsubsection{Task experiment data results}

To analyze which factors of the exhibit were more affected by the stereoscopic lighting, three sets of variables in this experiment were set up: changes in colour, detail, and modeling. In the experiment to find different tasks, there were three sets of variables, two kinds of lighting conditions (with or without stereoscopic lighting), and six stimulating VE. Participants would randomly perform

\begin{tabular}{|c|c|c|c|c|c|c|}
\hline & & & & & \multicolumn{2}{|c|}{$\begin{array}{c}95 \% \text { Confidence Interval } \\
\text { of the Difference }\end{array}$} \\
\hline & $\mathrm{t}$ & $\mathrm{df}$ & Sig.(2-tailed) & Mean Difference & Lower & Upper \\
\hline VAR01 & 8.230 & 17 & .000 & 2.52989 & 1.8813 & 3.1785 \\
\hline
\end{tabular}

Table 8: One-sample t-test of duration of fixation in the second experiment.

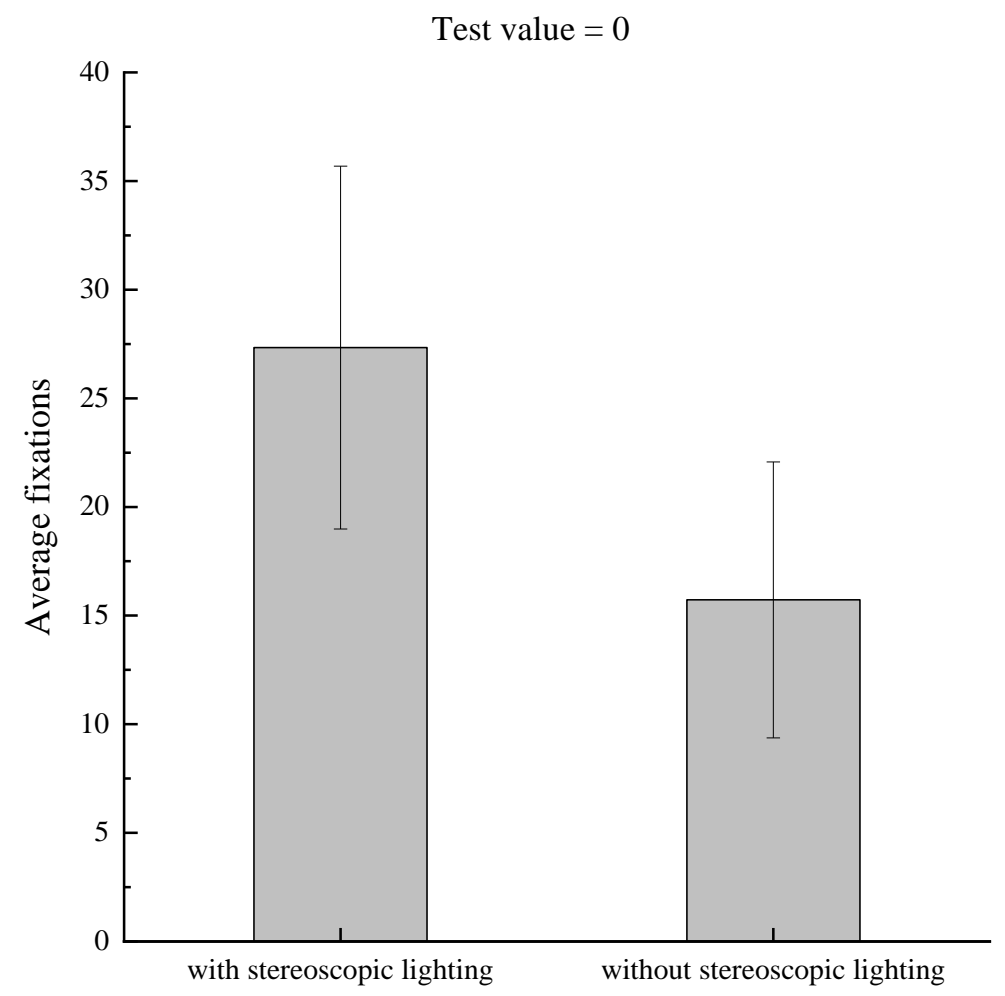

Figure 8: Average fixations in areas of interest with or without stereoscopic lighting in the second experiment. The error bars in this figure are the standard deviation of fixations.

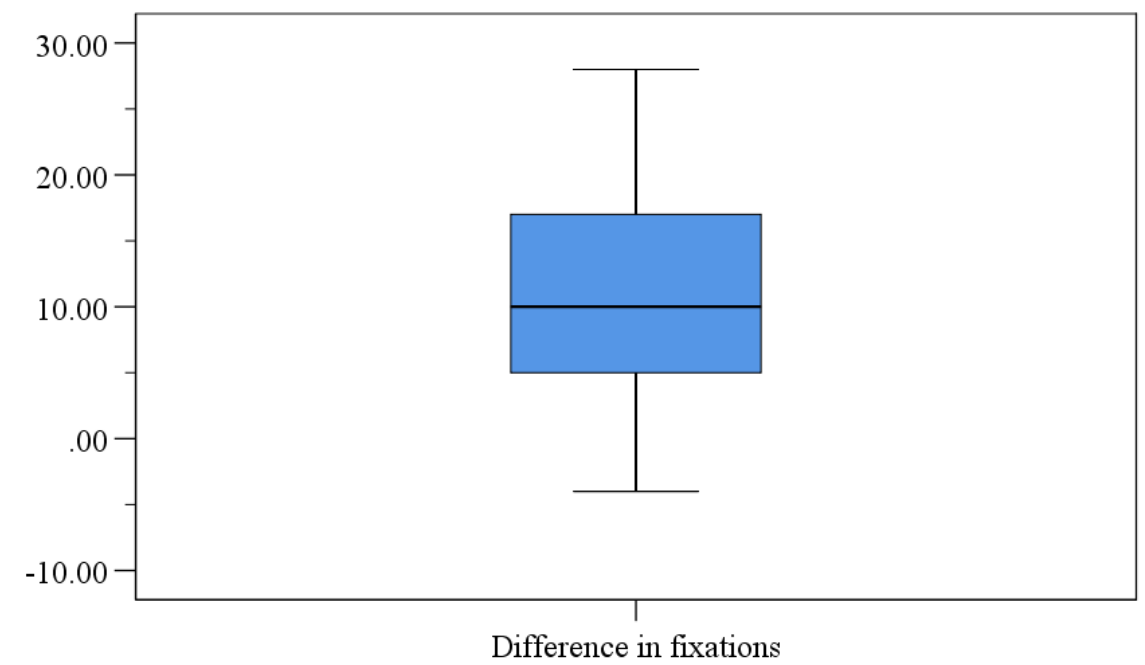

Figure 9: Box plot of the difference in fixations. 
different tasks in two scenes. Thirty-six participants were invited to the experiment in which we removed two invalid data and obtained a total of 70 data. The correct rate of finding change was counted and summarized in Table 11.

As shown from the above table, the factor most influenced by stereoscopic lighting was exhibit detail. The difference of correct rate between the VR with and without stereoscopic lighting was $12.5 \%$, which meant that the participants were able to see the details of the exhibits better in with stereoscopic lighting, including whether the patterns of the exhibits were raised and whether there were ice cracks and so on. Stereoscopic lighting had the secondary impact on the modeling and the least impact on the colour. For the exhibits with stereoscopic optimal lighting, the viewer can focus more attention on the details of the exhibits, which improves the ability of visual processing.

In addition to recording whether the subjects correctly found the difference-finding task changes, it also recorded

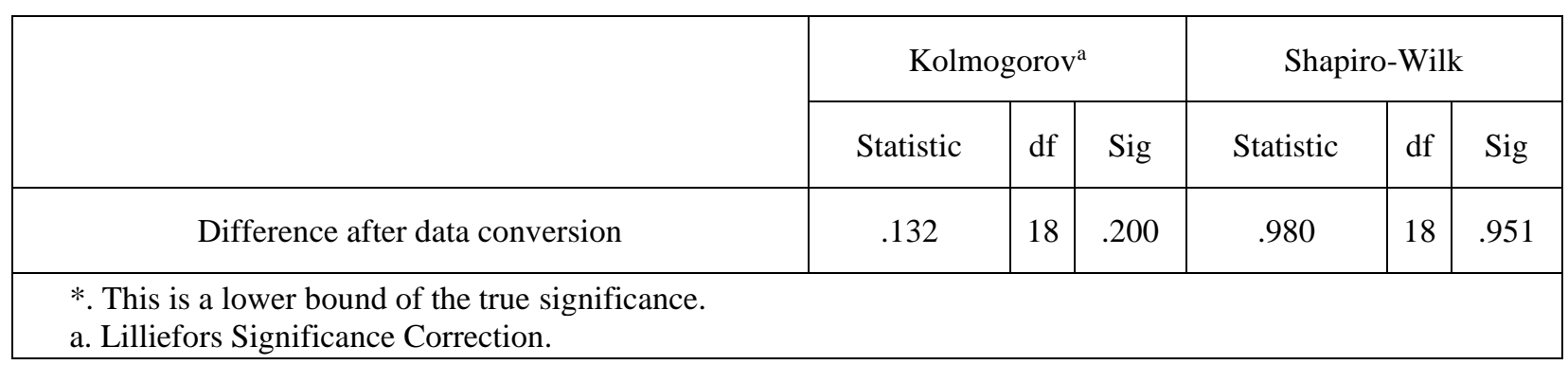

Table 9: Normality test of the difference in fixations.

\begin{tabular}{|c|c|c|c|c|c|c|}
\hline & & & & & \multicolumn{2}{|c|}{$\begin{array}{c}\text { 95\% Confidence Interval } \\
\text { of the Difference }\end{array}$} \\
\hline & $\mathrm{t}$ & $\mathrm{df}$ & Sig.(2-tailed) & Mean Difference & Lower & Upper \\
\hline VAR02 & 5.897 & 17 & .000 & 11.61111 & 7.4570 & 15.7652 \\
\hline
\end{tabular}

Table 10: One-sample t-test of fixation in the second experiment.

\begin{tabular}{|c|c|c|c|}
\hline & $\begin{array}{c}\text { Correct rate of scenes without } \\
\text { stereoscopic lighting }\end{array}$ & $\begin{array}{c}\text { Correct rate of scenes with } \\
\text { stereoscopic lighting }\end{array}$ & Difference \\
\hline colour & $93.75 \%$ & $100 \%$ & $6.25 \%$ \\
\hline detail & $87.50 \%$ & $100 \%$ & $12.50 \%$ \\
\hline modeling & $82.40 \%$ & $93.75 \%$ & $11.35 \%$ \\
\hline total & $87.75 \%$ & $97.95 \%$ & $10.20 \%$ \\
\hline
\end{tabular}

Table 11: Difference-finding task correct rate.

\begin{tabular}{|c|c|c|c|}
\hline \multicolumn{2}{|r|}{ Change type } & $\begin{array}{l}\text { Frequency of without } \\
\text { stereoscopic lighting }\end{array}$ & $\begin{array}{l}\text { Frequency of with } \\
\text { stereoscopic lighting }\end{array}$ \\
\hline \multirow{3}{*}{ colour } & Similar colour changes & $40 \%$ & $37.5 \%$ \\
\hline & Overall inverse colour changes & $26.7 \%$ & $25 \%$ \\
\hline & Partial inverse colour changes & $33.3 \%$ & $37.5 \%$ \\
\hline \multirow{2}{*}{ detail } & $\begin{array}{l}\text { Increase or decrease variation in } \\
\text { explanation card details }\end{array}$ & $57.1 \%$ & $41.2 \%$ \\
\hline & $\begin{array}{c}\text { Raised or flat decorative patterns } \\
\text { changes }\end{array}$ & $42.9 \%$ & $58.8 \%$ \\
\hline \multirow{2}{*}{ modeling } & Partial modeling changes & $14.3 \%$ & $33.3 \%$ \\
\hline & Overall shape changes & $85.7 \%$ & $66.7 \%$ \\
\hline
\end{tabular}

Table 12: Frequency statistics table for variables identified as changing for the first time. 
the variables that were changed for the first time in each search process. The frequency table was shown in Table 12 below. As Table 12 showed, there were three types of colour changes: similar colour changes and overall and partial inverse colour changes. The presence of stereoscopic lighting has little effect on the discovery frequency of the three colour changes from the results. That is, the existence of stereoscopic lighting has little relationship with the discovery of colour changes, and the existence of stereoscopic lighting will not improve viewers' attention to the colour of the exhibits. And then two types of changes were set up in the detailed task to increase or decrease variation in explanation card details and raised or flat decorative patterns changes. From the frequency results, the frequency of raised or flat decorative patterns changes of the exhibits with stereoscopic lighting was $15.9 \%$ higher than that of the exhibits without stereoscopic lighting. Because the exhibits' raised or flat decorative pattern may cause different visual effects due to stereoscopic lighting, the participants were more likely to find out the detailed changes. Two types of changes were set in the modeling task, partial or overall modeling changes. The result showed that the partial modeling changes were more likely to attract attention after the stereoscopic lighting was optimized, and the frequency increased by $19 \%$. Partial modeling changes would be more likely to attract the participants' attention due to the stereoscopic lighting, with a $19 \%$ increase in frequency. This result explained that raised or flat decorative patterns would cause different visual effects due to the stereoscopic lighting.

This result may explain that raised or flat decorative patterns would cause different visual effects due to the stereoscopic lighting. The participants were more likely to find out the detailed changes. Two types of changes were set in the modeling task, partial or overall modeling changes. The result showed that the partial modeling changes were more likely to attract attention after the stereoscopic lighting was optimized, and the frequency increased by $19 \%$. Partial modeling changes would be more likely to attract the participants' attention due to the stereoscopic lighting, with a $19 \%$ increase in frequency.

Combining the two tables, regardless of whether the VR design with stereoscopic lighting or not, the participants were susceptible to colour changes, and their correct rate was high. The frequency of finding the three types of colour changes were similar. As for the exhibits' modeling and detail, the participants were more likely to notice the changes after the VE was designed with stereoscopic lighting, and the frequency of the first finding was also significantly higher. Therefore, for exhibits with a decorative patterns or special partial modeling, more attention needs to be paid to design of these exhibits' stereoscopic lighting so that participants can more easily find their characteristics.

\section{Results}

In this study, the optimal stereoscopic values were simulated in a VR by comparison tests with and without stereoscopic lighting. The results found that the duration of fixation of AOI with stereoscopic lighting was $\mathrm{M}=5.18$ $\mathrm{s}$, and the duration of fixation of AOI without stereoscopic lighting was $\mathrm{M}=2.86 \mathrm{~s}$. The fixations of AIO with stereoscopic lighting was $\mathrm{M}=27.33$, and the fixations of AIO without stereoscopic lighting was $M=15.72$, the fixations of AIO with stereoscopic lighting accounted for $63.48 \%$ of the total number. This result indicated that exhibits with stereoscopic lighting could strengthen subjects' visual guidance and enhance the visual quality of appreciation.

In the task comparison test of "finding different changes" for visual identification in VR, there was a $6.25 \%$ difference in the correct rate of colour change, $12.5 \%$ difference in the correct rate of detail change, and $11.35 \%$ difference in the correct rate of modeling change of the utensils with or without stereoscopic lighting. The data showed that the design of stereoscopic lighting could effectively improve the visual performance of the observer. In analyzing the detected changes' first recognition rate, the frequency with stereoscopic lighting was $58.8 \%$ for the change in raised or flat decorative patterns changes, which was $15.9 \%$ higher than that without stereoscopic lighting. For partial inverse colour changes, the frequency with stereoscopic lighting was $37.5 \%$, with a $19 \%$ increase in recognition rate than that without stereoscopic lighting. This conclusion can guide museums in optimizing the lighting design for more detailed patterns and special modeling exhibits. However, for the three types of colour changes, only the frequency of partial inverse colour changes with stereoscopic lighting $(37.5 \%)$ was slightly higher than the frequency without stereoscopic lighting (33.3\%). Comparison of the frequency of the other two changes was lower than the frequency without stereoscopic lighting. It indicated that stereoscopic lighting had little effect on the visual guidance of colour changes. In the top-down cognitive task, for detail and modeling changes, the accuracy rate was higher with stereoscopic lighting, verifying that scenes with stereoscopic lighting design were better than those without stereoscopic lighting design from a cognitive perspective.

\section{Discussion}

Using immersive VR devices and eye-movement tracking technique can enhance the users' sense of immersion and providing a unique advantage for exploring people's visual attention [39]. It can greatly stimulate the users' visual sense and is used in different fields [40]. In the aspect of simulating physical lighting environment, VR is a better choice to replace the physical scene and many scholars have studied the human-factors lighting [41-43].

VR was applied in the research of museum stereoscopic lighting, which is not common in the past related research. Using eye-movement tracking technique to collect data can measure the salience indexes of human vision and improve the authenticity of the data [44].

There are some problems deserving discussion in this study. 
The first part of Experiment 1 was to fill in the subjective scale after watching the pictures on the computer screen, and analyze the data from the SD semantic scale to explore the influence of the independent variables on the comprehensive factor scores of the questionnaire. A participant needed to watch the stimulus materials 18 times, and the picture stimulus materials displayed on the screen may cause the visual fatigue problem in the observation experience of the participants. Using a computer screen to test the visual experience, the experiment needed to balance between the minimum amount of stimulus materials one participant watched and visual fatigue. And then, in the process of data analysis, there is no correlation between most independent variables and comprehensive factor scores. For the SD semantic scale, the establishment of regression equation may not be an appropriate analysis method.

The classification of the exhibits in Experiment 2 only involves color, detail, and modeling. Further research is needed on the texture and decorative elements of the exhibits.

In previous studies, simulated lighting experiment can be performed for a single exhibit by computer, but for a large range of space, testing the visual salience of multiple exhibits by contrast is difficult. Building a physical laboratory needs to install complex circuit system, it will surely consume a lot of resources. However, 3D models can be changed and used repeatedly in VR, effectively saving experimental costs of manpower and material [4546].

The difficulty of this subject is how to simulate the subtle changes of stereoscopic lighting to the maximum extent and control the complex lighting sources. Choosing $360^{\circ}$ panoramic rendering pictures or interactive $3 \mathrm{D}$ space in the VR depends on which situation can let experimental data be more accurately tested. Higuera et al, compared the psychological and physiological responses caused by two different display forms $\left(360^{\circ}\right.$ panoramic rendering pictures and interactive space) of VR and physical environment, finding that $360^{\circ}$ panoramic rendering pictures had the result that was most similar with physical scene [47].

According to the above conclusion, the study adopted high-precision $360^{\circ}$ panoramic rendering pictures, which can greatly reduce the risk of vertigo for participants. Using illumination analysis tool like V-Ray Light Meter can precisely control lighting conditions and eliminate other interference variables, improving the control accuracy of the experiment [48]. The participants can walk and watch freely in the three-dimensional space built by Unity3D, it is more beneficial to analyze participants' behavior in the museum. Improving the authenticity of the lighting environment and allowing participants to move freely in the VR as in the physical scene still requires new auxiliary tools or methods. Therefore, it is feasible to apply VR in the research of lighting environment [49].

Visual salience is a complex cognitive process, which requires comprehensive prediction for multiple evaluation results [50]. In VR, some traditional subjective scales and task selection questionnaires can be used together except for eye-movement tracking measurement. Eye-movement tracking can measure recessive visual physiological data, subjective scales can evaluate the overall experience of lighting environment and task questionnaires can evaluate the cognitive behavior of participants [51]. Previous studies have shown that there are no differences between in VR and traditional physical scene for the efficiency, satisfaction and experience impression of participants [52].

In addition, some technical limitations of VR had been found during the process of experiment. Firstly, in the physical scene, the participants will automatically adjust the observation distance with exhibits due to the size of exhibits. However, in this experiment, because the participants were in the $360^{\circ}$ panorama rendering pictures, the environment's center was set as the observation point, which was different with the situation that the participants in the physical scene. This setting affected the accuracy of experimental data. Secondly, the familiarity of participants with head-mounted virtual reality should be considered before the experiment. They needed to take 35 minutes for adaptation, which can be gradually reduced by practicing [53].

Although VR has some technical limitations, at present, we believe that the application of VR with eyemovement tracking and task judgmental testing is a good research method for museum lighting research.

\section{Declaration of conflicting interests}

The authors declared no potential conflicts of interest with respect to the research, authorship, and/or publication of this article.

\section{Funding}

The author(s) disclosed receipt of the follow-ing financial support for the research, author-ship, and/or publication of this article: This work was supported by the National Natural Science Foundation of China (Grant No. 51808232).

\section{References}

[1] Beijing Lighting Society Lighting Design Professional Committee. (2016). Lighting design handbook. 3rd ed. China Electric Power Publishing House (pp.361-364). Beijing.

[2] General Administration of Quality Supervision. (2009). GB/T 23863-2009. Design Code for Museum Lighting. Inspection and Quarantine and National Standardization Management Committee. China Standards Press, Beijing.

[3] Yang, G., Si, Y. (1987). Study on the visual environment of bronze ware, painted pottery and Tang tri-colored pottery showroom. Journal of Tongji University, (04), 38-51.

[4] Zhang, Q. (2007). Evaluation Index of Lighting Quality of Pedestrian Traffic Road in Main District. Journal of Chongqing University (Natural Science Edition), (08), 89-94.

[5] Chen, Z., Ma, Y., Hu, Y. (2009). Quality Index of Stereoscopic Lighting in Urban Lighting 
Environment. Journal of Chongqing University, 32(07), 839-843.

[6] Kadir, T and Brady, M. (2001). Saliency, scale and image description. International Journal of Computer Vision, 45, 83-105. https://doi.org/10.1023/A:1012460413855

[7] Itti, L., Koch, C., Niebur, E. (1998). A model of saliency-based visual attention for rapid scene analysis. IEEE Transactions on Pattern Analysis and Machine Intelligence, 20, 1254-1259. https://doi.org/10.1109/34.730558

[8] Nuthmann, A., Einhauser, W. (2015). A new approach to modeling the influence of image features on fixation selection in scenes. Ann N Y Acad Sci, 1339, 82-96. https://doi.org/10.1111/nyas.12705

[9] Coutrot, A., Hsiao, J. H., Chan, A.B. (2018). Scanpath modeling and classification with hidden Markov models. Behav Res Methods, 50, 362-379. https://doi.org/10.3758/s13428-017-0876-8

[10] Scheer, F. A., Buijs, R.M. (1999). Light affects morning salivary cortisol in humans. Journal of Clinical Endocrinology and Metabolism, 84, 33953398. https://doi.org/10.1210/jcem.84.9.6102

[11] Zheng, S. Q., Luo, R., Ye, M. (2015). The effect of dynamic light on human alertness. Journal of Lighting Engineering, 27(06), 1-5. https://doi.org/10.1109/SSLCHINA.2015.7360706

[12] Juslén, H. (2006). Influence of the colour temperature of the preferred lighting level in an industrial work area devoid of daylight. Ingineria Iluminatului, 8, 25-36,

[13] Zhu, Y. Y., Yang M. Q., Yao Y, Xiong X, Zhou G. (2017). The effect of indoor illumination on cognitive processing: The mediating role of subjective mood and alertness. Psychological Science, 40(06), 1328-1334.

[14] Xiong, X., Zhu, Y., Chen, Q., Ru, T., Zhou, G. (2018). The effects of indoor illumination and time of day on vigilance and visual-spatial performance. Psychological Science, 41(06), 1325-1332.

[15] Zhang, P., Wang, R. (2004). Image salient region detection based on viewpoint transfer and vision tracking. Journal of Software, (06), 891-898.

[16] Just, M. A., Carpenter, P. A. (1980). A theory of reading: From eye fixations to comprehension. Psychological review, 87, 329,

[17] Rayner, K. (1998). Eye movements in reading and information processing: 20 years of research. Psychological bulletin, 124, 372.

[18] Liversedge, S., Gilchrist, I., Everling, S. (2011). The Oxford handbook of eye movements. Oxford University Press.

[19] Yang, Y. N., Xiang, C. H., Rao, L. B., Tan, F. (2018). Building Virtual Human Science Museum with Virtual Reality Technology. Journal of Anatomy, 41(04), 488-489.

[20] Chen, Y., Cui, Z. and Hao, L. (2019). Virtual reality in lighting research: Comparing physical and virtual lighting environments. Lighting Research Technology, 51, 820-837. https://doi.org/10.1177/1477153518825387
[21] Xu, C., Zhou, C., Lin, Y. D. (2018). Comparison of different color temperature preferences based on real and virtual light environments. China Illuminating Engineering Journal , 29(03), 6-11+33.

[22] Boyles, M., Rogers, J., Goreham, K., Frank, M. A., Cowan, J. (2009, March). Virtual simulation for lighting \& design education. In 2009 IEEE Virtual Reality Conference (pp. 275-276). IEEE. https://doi.org/10.1109/VR.2009.4811052

[23] Blandet, T., Coutelier, G., Meyrueis, P. (2011, April). Virtual reality to simulate large lighting with high efficiency LEDs. In SPIE Eco-Photonics 2011: Sustainable Design, Manufacturing, and Engineering Workforce Education for a Green Future (Vol. 8065, pp. 806514). International Society for Optics and Photonics. https://doi.org/10.1117/12.894431

[24] Kim, B., Xylakis, E., Predescu, A. D., Triantafyllidis, G., Hansen, E. K., Mullins, M. (2017). Designing a Lighting Installation Through Virtual Reality Technology-The Brighter Brunnshög Case Study. In Interactivity, Game Creation, Design, Learning, and Innovation (pp. 43-53). Springer, Cham. https://doi.org/10.1007/978-3-319-76908-0_5

[25] Balocco, C. and Volante, G. (2018). Lighting Design for Energy Sustainability, Information, and Perception. A Museum Environment as a Case Study. Sustainability, 10. https://doi.org/10.3390/su10051671

[26] Zhang, L. (2015). Research for the display cabinet in museum. Journal of Nanjing Institute of the Arts (Art and design), (05), 201-205.

[27] Li, F. (2015). Discussion for design of Museum Exhibitions in visual environment. Shanxi: Shanxi University, China.

[28] Shi, X. (2017). A preliminary study on the display design of ceramic exhibition in museum. Graduate school of Chinese academy of social sciences, China.

[29] Yang, G., Si, Y. (1987). Study on bronze ware, ed pottery and Tang Tri-color of display room in VR. Journal of Tongji University, (04), 38-51

[30] Yang, G. (1985). Vision and visual environment. Shanghai: Tongji University Press, 104.

[31] Goulding, C. (2000). The museum environment and the visitor experience. European Journal of marketing, 34(3/4), 261-278.

[32] Kottasz, R. (2006). Understanding the Influences of Atmospheric Cues on the Emotional Responses and Behaviours of Museum Visitors. Journal of Nonprofit \& Public Sector Marketing, 16, 95-121. https://doi.org/10.1300/J054v16n01_06

[33] Forrest, R. (2013). Museum Atmospherics: The Role of the Exhibition Environment in the Visitor Experience. Visitor Studies, 16, 201-216. https://doi.org/10.1080/10645578.2013.827023

[34] Quartier, K., Vanrie, J. and Van Cleempoel, K. (2014). As real as it gets: What role does lighting have on consumer's perception of atmosphere, emotions and behaviour? Journal of Environmental Psychology, 39, 32-39. 
https://doi.org/10.1016/j.jenvp.2014.04.005

[35] Hagtvedt, H., Patrick, V.M. and Hagtvedt, R. (2008). The Perception and Evaluation of Visual Art. Empirical Studies of the Arts, 26, 197-218. https://doi.org/10.2190/EM.26.2.d

[36] Ko, T.-K., Kim, I.-T., Choi, A.-S. and Sung, M. (2016). Simulation and perceptual evaluation of fashion shop lighting design with application of exhibition lighting techniques. Building Simulation, 9, 641-658. https://doi.org/10.1007/s12273-016-0312-5

[37] Li, J. (2018). Study on Evaluation and Design Method of Landscape Lighting Quality in Traditional Chinese Style Architecture. Chongqing: Chongqing University.

[38] Huang, H., Chen, G. (2010). Present situation of lighting in university classrooms and subjective evaluation of visual environment. Lamp and Illumination, 34(04), 22-26

[39] Tang, M. and Auffrey, C. (2018). Advanced digital tools for updating overcrowded rail stations: using eye tracking, virtual reality, and crowd simulation to support design decision-making. Urban Rail Transit, 4, 249-256,

[40] Gallace, A., Ngo, M. K., Sulaitis, J., Spence, C. (2012). Multisensory presence in virtual reality: possibilities \& limitations. In Multiple sensorial media advances and applications: New developments in MulSeMedia (pp. 1-38). IGI Global.

[41] Suzer, O.K., Olgunturk, N. and Guvenc, D.J.D. (2018). The effects of correlated colour temperature on wayfinding: A study in a virtual airport environment. Displays, 51, 9-19. https://doi.org/10.1016/j.displa.2018.01.003

[42] Vehlen, A., Spenthof, I., Tönsing, D., Heinrichs, M. and Domes, G. (2021). Evaluation of an eye tracking setup for studying visual attention in face-to-face conversations. Scientific reports, 11, 1-16. https://doi.org/10.1038/s41598-021-81987-x

[43] Marquardt, G. (2011). Wayfinding for people with dementia: a review of the role of architectural design. HERD: Health Environments Research Design Journal, 4, 75-90. https://doi.org/10.1177/193758671100400207

[44] Vehlen, A., Spenthof, I., Tönsing, D., Heinrichs, M., Domes, G. (2021). Evaluation of an eye tracking setup for studying visual attention in face-to-face conversations. Scientific reports, 11, 1-16. https://doi.org/10.1038/s41598-021-81987-x

[45] Meißner, M., Pfeiffer, J., Pfeiffer, T., Oppewal, H. (2019). Combining virtual reality and mobile eye tracking to provide a naturalistic experimental environment for shopper research. Journal of Business Research, 100, 445-458. https://doi.org/10.1016/j.jbusres.2017.09.028

[46] Wu Z., Empirical Study on the Optimization Strategy of Subject Metro Design Based on Virtual Reality. Informatica, 42(3).

https://doi.org/10.31449/inf.v42i3.2424
[47] Higuera-Trujillo, J.L., Maldonado, J.L.-T., Millán, C.L. (2017). Psychological and physiological human responses to simulated and real environments: A comparison between Photographs, 360 Panoramas, and Virtual Reality. Applied ergonomics, 65, 398 409. https://doi.org/10.1016/j.apergo.2017.05.006

[48] Koylazov V. (2018). How to set up lighting analysis in v-ray next.

[49] Chen, Y., Cui, Z., Hao, L. (2019). Virtual reality in lighting research: Comparing physical and virtual lighting environments. Lighting Research Technology, 51, 820-837. https://doi.org/10.1177/1477153518825387

[50] Xia, Z., Hélène, S., Ming-Quan, Z. (2010). Application of Virtual Reality Technology for Neuropsychological Assessment. Advances in Psychological Science, 18, 511.

[51] Chen, H., Chou, C., Luo, H., Luo, M. (2016). Museum lighting environment: Designing a perception zone map and emotional response models. Lighting Research Technology, 48, 589607. https://doi.org/10.1177/1477153515596456

[52] Rieuf, V., Bouchard, C., Aoussat, A. (2015). Immersive moodboards, a comparative study of industrial design inspiration material. Journal of Design Research, 13, 78-106. https://doi.org/10.1504/JDR.2015.067233

[53] Lopez, M.C., Deliens, G., Cleeremans, A.J.R.n. (2016). Ecological assessment of divided attention: what about the current tools and the relevancy of virtual reality. Revue neurologique, 172, 270-280. https://doi.org/10.1016/j.neurol.2016.01.399 
